\title{
HUBUNGAN TINGKAT PENDIDIKAN DAN EKONOMI TERHADAP PEMBERIAN PENDIDIKAN SEKS PADA USIA DINI
}

\author{
Dewi Zolekhah ${ }^{1}$, Liberty Barokah ${ }^{2}$ \\ Prodi Studi Kebidanan (D3) Universitas Jenderal Achmad Yani Yogyakarta ${ }^{1,2}$ \\ dewizolekhah87@gmail.com², aleafeda12@gmail.com
}

\begin{abstract}
Recently, many cases of child abuse have occurred in the world, one of which is in Indonesia. Cases of violence in early childhood are caused by various triggering factors, one of which is the lack of seks education in early childhood provided by parents. An understanding of the knowledge and availability of parental skills is needed to start seks education in early childhood. This study aims to determine the relationship between the level of education and the economy of parents on the provision of seks education in early childhood. The research was conducted at TKIT Alhamdulillah Tamantirto Kasihan Bnatul from October 1 to October 31, 2019. This type of research is descriptive analytic research with a cross sectional study approach with a sampling technique using total sampling with a total sample of 67 respondents. Data analysis using chi-square test. $p$ value of $0.000<0.05$ so it can be concluded that there is a relationship between the level of education with the provision of seks education in early childhood. In the economic variable, it was found that the $p$ value was $0.135>0.05$, so it can be concluded that there is no relationship between the economic level and the behavior of providing seks education for children. for parents and teachers, namely increasing attention to children in providing seks education continuously according to their age and development.
\end{abstract}

Keywords $\quad$ : Education, Economics, Early Seks

\begin{abstract}
ABSTRAK
Kasus kekerasan anak belakangan terakhir banyak terjadi di dunia salah satunya yaitu di Indonesia. Kasus kekerasan pada anak usia dini, disebabkan oleh berbagai faktor pemicu salah satunya adalah kurangnya pendidikan seks pada anak usia dini yang diberikan oleh orang tua. Pemahaman tentang pengetahuan dan ketersediaan keterampilan orang tua sangat diperlukan untuk memulai pendidikan seks pada anak usia dini. Penelitian ini bertujuan untuk mengetahui hubungan tingkat pendidikan dan ekonomi orang tua terhadap pemberian pendidikan seks pada anak usia dini. Penelitian dilakukan di TKIT Alhamdulillah Tamantirto Kasihan Bantul mulai tangga 1 Oktober - 31 Oktober 2019. Jenis penelitian ini yaitu penelitian deskriptif analitik dengan pendekatan studi cross sectional dengan teknik pengambilan sampel menggunakan Total sampling dengan total sampel 67 responden. Analisis data dengan menggunakan uji chi-square. Nilai $p$ value sebesar $0.000<0,05$ sehingga dapat disimpulkan bahwa terdapat hubungan antara tingkat pendidikan dengan pemberian pendidikan seks pada anak usia dini. Pada variabel ekonomi didapatkan hasil bahwa nilai $p$ value $0.135>0,05$ sehigga bisa disimpulkan bahwa tidak ada hubungan antara tingkat ekonomi dengan perilaku pemberian pendidikan seks untuk anak. untuk orang tua dan guru yaitu meningkatkan perhatian kepada anak dalam pemberian pendidikan seks secara terus menerus sesuai usia dan perkembangannya.
\end{abstract}

Kata Kunci : Pendidikan, Ekonomi, Seks Usia Dini

\section{PENDAHULUAN}

Kasus kekerasan pada anak beberapa tahun terakhir banyak terjadi di dunia termasuk salah satunya adalah di Indonesia. Anak-anak hingga usia remaja selalu dijadikan target empuk para pelaku kejahatan seks. Angka kejadian selalu meningkat seiring dengan banyaknya jumlah penduduk, serta media teknologi yang semakin bervariasi macamnya. Terdapat banyak faktor yang jauh lebih berperan sangat penting dibandingkan media, yaitu diantaranya pola asuh orang 
tua, lingkungan, penanaman etika dan pengetahuan pada anak dll (Magdalena, 2010). Kasus di Jakarta Timur, tindakan pencabulan pada lebih dari satu anak perempuan dibawah umur (Setyawan, 2019). Kasus di Bantul, pelecehan seksual dengan memegang kemaluan pada anak laki-laki berusia 6 tahun, perlakuan tersebut menyebabkan anak sakit saat hendak buang air kecil karena mengalami trauma (Ariyanti, 2014).Komnas Perempuan telah memposisikan DIY pada urutan ke-4 sebagai provinsi paling banyak kasus kekerasan terhadap perempuan dan anak (Kumparan, 2018).

Komisi Nasional Perlindungan Anak juga menyempatkan untuk mengunjungi kota Yogyakarta karena DIY disebut darurat kejahatan seksual (Gil, 2018). Fenomena kekerasan dan penyimpangan seks yang menimpa anak disebabkan oleh beberapa faktor, salah satunya adalah kurangnya pendidikan seks pada anak usia dini terutama yang diberikan oleh orang tua sebagai orang yang paling dekat dengan anak. Pendidikan seks sejatinya sudah harus diberikan sejak dini. Proses pengajaran materi pendidikan seks yang benar membutuhkan proses yang panjang sejak anak lahir sampai tahap remaja akhir (Nugraha \& Wibisono, 2016). Faktor budaya yang menganggap membicarakan seks adalah hal porno termasuk masyarakat banyak beranggapan bahwa pendidikan ini mengajarkan cara berhubungan badan, padahal sebetulnya tidak.

Pendidikan seks berbeda dengan pengetahuan reproduksi karena pengetahuan reproduksi sangat berkaitan dengan proses perkembangbiakan makhluk hidup. ${ }^{10}$ Usia dini juga merupakan usia yang sangat menentukan dalam pembentukan karakter dan kepribadian anak. Pada usia ini penting bagi pengembangan intelegensi permanen dirinya. Sesuai dengan keunikan dan pertumbuhan anak usia dini maka penyelenggra pendidikan kesehatan reproduksi penting bagi anak usia dini disesuikan dengan tahap-tahap selanjutnya (Wini \& Nurhasmah, n.d.).
Pendidikan seksual adalah tanggung jawab keluarga terutama orang tua. Keluarga memiliki peranan yang sangat penting karena keluarga merupakan tempat membangun pondasi belajar anak yang pertama dan utama bagi anak. Lingkungan keluarga merupakan lingkungan awal bagi seorang anak, segala tingkah laku maupun perkembangan yang muncul pada diri anak akan mencontoh pada kedua orangtuanya (Muhammad, 2012). Berawal dari pemahaman masyarakat yang masih pro kontra mengenai pendidikan seks pada anak dan banyaknya orang tua yang merasa malu dan rikuh harus memulai dari mana dalam membicarakannya pada anak dan orang tua juga mempunyai anggapan bahwa pendidikan seks belum pantas untuk diberikan atau diperbincangkan pada anak usia dini.

Pendidikan seks yang tidak diberikan di usia dini mengakibatkan tingginya kekerasan seksual pada anak yang dilakukan orang-orang terdekat anak termasuk keluarga. Fenomena ini menunjukkan pentingnya pemahaman akan pendidikan seks pada anak usia dini. Masalah pendidikan seks pada saat ini kurang diperhatikan orang tua sehingga mereka menyerahkan semua pendidikan anak kepada sekolah termasuk pendidikan seks. Berdasarkan latar belakang tersebut maka dilakukan penelitian ini dengan tujuan mengetahui hubungan tingkat Pendidikan dan tingkat ekonomi dengan perilaku pemberian pendidikan seks usia dini.

\section{METODE}

Jenis penelitian yang digunakan adalah penelitian analitik korelasi dengan pendekatan waktu cross sectional. Populasi dalam penelitian seluruh ibu yang mempunyai anak usia dini yang bersekolah di PG-TKIT Alhamdulilah. Teknik pengambilan sampel dengan total sampling yaitu mengambil seluruh sampel yang ada (Sugiyono, 2016). Jumlah sampel dalam penelitian ini adalah 67 orang. Penelitian dilakukan mulai tanggal 1 Agustus - 31 
Oktober 2021. Analisis biraviat digunakan untuk melihat kemungkinan hubungan atau korelasi antar masing-masing variabel independen dengan variabel dependen. Analisis data bivariat menggunakan Chi Square.

\section{HASIL}

Responden adalah orang tua yang mempunyai anak berumur 4-5 tahun yang bersekolah di PG-TKIT Alhamdulilah Tamantirto, Kasihan, Bantul Yogyakarta. Jumlah keseluruhan populasi adalah 90 orang, saat dilakukan penelitian hanya 67 orang yang bersedia menjadi responden.

\section{Distribusi Frekuensi Berdasarkan Tingkat Pendidikan}

Tabel 1 Distribusi Frekuensi Berdasarkan Tingkat Pendidikan

\begin{tabular}{lcc}
\hline $\begin{array}{l}\text { Tingkat } \\
\text { Pendidikan }\end{array}$ & Frekeunsi & $(\%)$ \\
\hline Rendah & 8 & 10.5 \\
Tinggi & 59 & 89.5 \\
\hline Total & 67 & 100
\end{tabular}

Sumber : Data Primer 2019

Berdasarkan tabel 1 dapat diketahui bahwa tingkat pendidikan responden dalam kategori tinggi (SMA dan akademi/perguruan tinggi) sebanyak 60 $(89,5 \%)$.

\section{Distribusi Frekuensi Berdasarkan Tingkat Ekonomi}

Tingkat ekonomi responden diukur berdasarkan pengeluaran keluarga per bulan terdiri dari biaya makan, pendidikan, dan transportasi. Tingkat ekonomi responden dikategorikan menjadi dua yaitu tingkat ekonomi rendah dan tingkat ekonomi tinggi. Penentuan kategori berdasarkan Cut Off Point yang di ambil berdasarkan nilai median distribusi data jumlah pengeluaran responden, didapatkan nilai cut off point adalah Rp 1.900.000. Responden dengan jumlah pengeluaran keluarga kurang dari $\mathrm{Rp}$ 1.900.000 masuk dalam kategori tingkat ekonomi rendah, dan responden dengan pengeluaran keluarga lebih dari Rp 1.900.000 masuk dalam kategori tingkat ekonomi tinggi.

Tabel 2 Distribusi Frekeunsi Berdasarkan Tingkat Ekonomi

\begin{tabular}{lll}
\hline Pengeluaran & Frekeunsi & (\%) \\
& & \\
\hline$<$ Rp 1.900.000 & 31 & 46.3 \\
$\geq$ Rp 1.900.000 & 36 & 53.7 \\
\hline Total & 67 & 100
\end{tabular}

Sumber : Data Primer 2019

Berdasarkan tabel 2 dapat diketahui bahwa responden sebagian besar masuk dalam kategori tingkat ekonomi tinggi yaitu $36(53,7 \%)$.

\section{Hubungan Antara Tingkat Pendidikan Dengan Perilaku Pemberian Pendidikan Seks Untuk Anak}

Tabel 3 Hubungan Antara Tingkat Pendidikan Dengan Perilaku Pemberian Pendidikan Seks Untuk Anak

\begin{tabular}{|c|c|c|c|c|c|c|c|}
\hline \multirow{3}{*}{ Tingkat Pendidikan } & \multicolumn{4}{|c|}{ Perilaku } & \multirow[t]{2}{*}{ Total } & \multirow{2}{*}{\multicolumn{2}{|c|}{$P$ Value }} \\
\hline & \multicolumn{2}{|c|}{$\begin{array}{l}\text { Tidak memberi } \\
\text { Pendidikan Seks }\end{array}$} & \multicolumn{2}{|c|}{$\begin{array}{c}\text { Member Pendidikan } \\
\text { Seks }\end{array}$} & & & \\
\hline & $\mathbf{N}$ & $\%$ & $\mathbf{n}$ & $\%$ & $\mathbf{n}$ & $\%$ & \\
\hline Rendah & 6 & 8.9 & 2 & 2.99 & 8 & 11.8 & 0.025 \\
\hline Tinggi & 20 & 29.9 & 39 & 58.21 & 59 & 88.1 & \\
\hline Total & 26 & 38.8 & 41 & 61.2 & 67 & 100 & \\
\hline
\end{tabular}

Berdasarkan tabel 3 dapat diketahui bahwa terdapat 6 responden dengan tingkat pendidikan rendah memberikan memberikan informasi pendidikan seks 
sebanyak 2 (2.99\%), dan terdapat 20 responden dengan pendidikan tinggi tidak memberikan pendidikan seks sebanyak 20 (29,9\%). Berdasarkan hasil uji Chi square didapatkan hasil $p$ value sebesar $0.025<$
0.05. Dapat di simpulkan bahwa terdapat hubungan antara tingkat pendidikan dengan perilaku pemberian pendidikan seks pada anak.

\section{Hubungan Antara Tingkat Ekonomi Dengan Perilaku Pemberian Pendidikan Seks Untuk Anak}

Tabel 4 Hubungan Antara Tingkat Ekonomi Dengan Perilaku Pemberian Pendidikan Seks Untuk Anak

\begin{tabular}{llllllll}
\hline \multirow{2}{*}{$\begin{array}{c}\text { Tingkat } \\
\text { Ekonomi }\end{array}$} & \multicolumn{9}{c}{ Perilaku } & \multicolumn{2}{c}{ Total } & \multirow{2}{*}{$\boldsymbol{P}$ Value } \\
\cline { 2 - 7 } & $\begin{array}{l}\text { Tidak } \\
\text { Pendidikan Seks }\end{array}$ & \begin{tabular}{l} 
memberikan \\
\cline { 2 - 7 }
\end{tabular} & $\begin{array}{l}\text { Memberikan } \\
\text { Pendidikan Seks }\end{array}$ & & \\
\hline Rendah & $\mathrm{n}$ & $\%$ & $\mathrm{n}$ & $\%$ & $\mathrm{n}$ & $\%$ & \\
Tinggi & 15 & 22.5 & 16 & 23.9 & 31 & 46.4 & 0.135 \\
\hline Total & 11 & 17.3 & 25 & 37.3 & 36 & 54.6 & \\
\hline
\end{tabular}

Berdasarkan tabel 4 dapat diketahui bahwa terdapat $16(23.9 \%)$ responden dengan tingkat ekonomi rendah memberikan pendidikan seks untuk anak, dan terdapat 11 responden dengan tingkat ekonomi tinggi sebanyak $11 \quad(17.3 \%)$ responden tetapi tidak memberikan pendidikan seks untuk anak. Hasil uji cqi square didapatkan nilai $p$ value $0.135>0,05$ sehigga bisa disimpulkan bahwa tidak ada hubungan antara tingkat ekonomi dengan perilaku pemberian Pendidikan seks untuk anak.

\section{PEMBAHASAN}

\section{Tingkat Pendidikan Dengan Pemberian Pendidikan Seks}

Berdasarkan hasil penelitian pada tabel 1 dapat diketahui bahwa mayoritas responden adalah berpendidikan tinggi (tamat SMA dan PT) yaitu sejumlah 59 responden $(89.5 \%)$. Pendidikan seseorang berpengaruh terhadap penerimaan informasi, salah satunya tentang pendidikan seks. Seseorang yang berpendidikan tinggi akan lebih terbuka menerima informasi. Berbeda halnya orangtua yang mempunyai pendidikan rendah, akan cenderung tidak terbuka menerima informasi dari luar, bahkan tidak jarang mereka sering beranggapan bahwa masalah pendidikan seks adalah hal yang tabu (Sujarwati et al.,
2014). Berdasarkan uji bivariat pada tabel 3 hasil uji Chi Square, diperoleh p-value sebesar 0,025 yang artinya terdapat hubungan antara tingkat pendidikan dengan perilaku pemberian pendidikan seks pada anak. Semakin tinggi tingkat pendidikan orang tua, maka akan semakin mudah untuk menerima suatu informasi khususnya informasi tentang pendidikan seks, dengan harapan orang tua yang berpendidikan tinggi akan semakin luas tingkat pengetahuannya terutama tentang seks (Wawan \& Dewi, 2011).

Penelitian Maryuni menyatakan ada hubungan yang bermakna antara pendidikan dengan tingkat pengetahuan orang tua tentang pendidikan seks secara dini pada anak (Maryuni \& Anggraeni, 2016). Namun hasil penelitian diatas berbeda dengan penelitian sebelumnya yang dilakukan oleh Anisah (2009) di Cianjur, Jawa Barat yang menyatakan bahwa tidak ada hubungan yang signifikan antara pendidikan dengan tingkat pengetahuan orang tua terhadap pendidikan yaitu dengan p-value 0,717. Perbedaan dari hasil penelitian yang dilakukan dengan hasil penelitian Anisah (2009) dikarenakan peneliti lain melakukan penelitian di daerah pedesaan yang sebagian besar masyarakatnya berpendidikan rendah sehingga pengetahuan mereka akan pendidikan seksual masih sangat minim(Anisah \& Ani, 2009). 


\section{Tingkat Ekonomi Dengan Pemberian Pendidikan Seks}

Berdasarkan uji bivariat pada tabel 4 didapatkan hasil bahwa tidak terdapat hubungan yang signifikan antara tingkat ekonomi dengan perilaku pemberian pendidikan seks untuk anak ( $p$ value $>0.05$ ). Pada penelitian yang dilakukan oleh Imanda 2012, didapatkan bahwa tidak terdapat hubungan antara ekonomi dengan pendidikan seks. Hal ini sesuai dengan hasil penelitian Syaputri, 2014 yang menyatakan bahwa tidak terdapat hubungan antara status ekonomi dengan perilaku pemberian seks. Status ekonomi yang dimaksud disini adalah pendapatan ayah dan ibu.(Syaputri, 2014) Menurut Ali (2011) orangtua adalah orang yang dianggap tua, cerdik, pandai dalam keluarga Seorang ayah disamping memiliki kewajiban untuk mencari nafkah bagi keluarga, dia juga berkewajiban untuk mencari tambahan ilmu bagi dirinya (Ali \& Asrori, 2011). Seorang ayah akan dapat membimbing dan mendidik diri sendiri dan keluarganya menjadi lebih baik dengan ilmu yang dimilikinya khususnya tentang pendidikan seks. seorang ibu disamping memiliki kewajiban dalam pemeliharaan keluarga, seorang ibu pun tetap memiliki kewajiban dalam mencari ilmu termasuk tentang pendidikan seks. Hal itu penting karena seorang anak akan lebih dekat dengan ibunya.

Pada penelitian ini tingkat ekonomi diukur berdasarkan total pengeluaran per bulan dalam keluarga yang terdiri dari makan tiap hari, pendidikan dan transportasi, dimana rata-rata pengeluaran terbesar yang dikeluarkan oleh orang tua sehari-hari adalah kebutuhan untuk makan. Pengeluaran yang paling sedikit nominalnya adalah pengeluaran untuk kebutuhan transportasi sehari-hari.

Dari uraian diatas dapat diketahui bahwa tingkat Pendidikan orang tua mempengaruhi pola perilaku pemberian Pendidikan seks pada anak usia dini. Semakin tinggi Pendidikan maka orang tua akan secara dini memberikan Pendidikan seks pada anak. Tingkat ekonomi tidak berhubungan dengan perilaku pemberian Pendidikan seks usia dini pada anak. Semakin tinggi atau semakin rendah tidak berpengaruh terhadap pola pemberian edukasi seks pada anak.

\section{KESIMPULAN}

Terdapat hubungan antara tingkat pendidikan dengan pemberian pendidikan seks pada anak usia dini dan Tidak terdapat hubungan anatar Pendidikan orang tua dengan pemberikan Pendidikan seks.

\section{UCAPAN TERIMAKASIH}

Terimakasih kepada Lokasi penelitian yaitu TKIT Alhamdulillah. Para peneliti serta pihak yang telah berpartisipasi dalam penyelesaian penelitian ini.

\section{DAFTAR PUSTAKA}

Ali, M., \& Asrori, M. (2011). Psikologi Remaja: Perkembangan peserta didik. Bumi Aksara.

Anisah, \& Ani. (2009). Faktor-faktor yang berhubungan dengan pengetahuan dan sikap Orang tua Terhadap pendidikan Seksual di Kampung Parabon RW 03 Desa Cilota kabupaten Cianjur. Universitas Indonesia.

Ariyanti, S. (2014). Bocah 6 Tahun di Bantul Jadi Korban Pelecehan Seksual. Tribunnnews.

http://jogja.tribunnews.com/2014/06/1 6/bocah-6-tahun-di-bantul-jadikorban-pelecehan-seksual

Gil. (2018). DIY Darurat Kejahatan Seksual Anak. Tribunnews.

Kumparan. (2018). Kekerasan Terhadap Perempuan dan Anak di DIY Terbanyak Ke-4 Nasional. https://kumparan.com/tugujogja/kasus -kekerasan-terhadap-perempuan-dananak-di-yogyakarta-duduki-urutan-4nasional-1536155631812215928

Magdalena, M. (2010). Melindungi Anak 
Dari Seks Bebas. PT.GrasindoGramedia.

Maryuni, \& Anggraeni, L. (2016). Faktor yang berhubungan dengan tingkat pengetahuan Orang Tua tentang Pendidikan Seks secara dini pada anak sekolah dasar (SD). Jurnal Ners Dan Kebidanan Indonesia.

Muhammad, F. (2012). Desain Pembelajaran Paud. Ar-Ruz Media.

Nugraha, D., \& Wibisono, S. (2016). Adik Bayi Datang dari Mana?: A-Z Pendidikan Seks Usia Dini. Noura Books.

Setyawan, D. (2019). Pelaku Kekerasan Terhadap Anak Ditangkap. Diunduh pada 20 Mei 2019. KPAI. http://www.kpai.go.id/berita/kpaipelaku-kekerasan-seksual-terhadapanak-ditangkap

Sugiyono. (2016). Sugiyono, Metode Penelitian. Sugiyono.

Sujarwati, Yugistyowati, A., \& Haryani, K. (2014). Peran Orang Tua dan Sumber Informasi dalam Pendidikan Seks Dengan Perilaku Pendidikan Seksual
Remaja pada Masa Pubertas di SMAN Turi. Jurnal Ners Dan Kebidanan Indonesia, 2, 112-116.

Syaputri, P. (2014). Hubungan Tingkat Pendidikan, Status Ekonomi, dan Lingkungan dengan Prilaku Seks Remaja (14 - 17 tahun) di Gampong Kuta Padang Kecamatan Johan Pahlawan Kabupaten Aceh Barat. Fakultas Kesehatan Masyarakat Universitas Teuku Umar Meulaboh.

Wawan, A., \& Dewi, M. (2011). Teori Dan Pengukuran Pengetahuan, Sikap Dan Perilaku Manusia. Nuha Medika.

Wini, \& Nurhasmah. (n.d.). Implementasi Pendidikan Seksual Untuk Anak Usia Dini : Studi Kasus di Taman KanakKanak Salman Al Farisi Kota Bandung Tahun Pelajaran 2014-2015. Universitas Pendidikan Indonesia. 